\title{
Frequency of different shell color and its effect on the fertility and hatchability in Black rock, Gramapriya and Vanaraja breeds of chicken
}

\author{
Abhay Kumar ${ }^{1}$, Keshab Das ${ }^{2}$, K. Mukherjee ${ }^{3}$, A. Bharti ${ }^{4}$ and A.K. Singh ${ }^{5}$ \\ 1. Birsa Agricultural University, Ranchi; 2. College of Veterinary Science \& AH, Durg (CG); \\ 3. College of Veterinary Science \& AH, Durg (CG); 4. Birsa Agricultural University, Ranchi; \\ 5. Indian Veterinary Research Institute, Izatnagar \\ Corresponding author: Abhay Kumar, email: absinghks@yahoo.com \\ Received: 28-03-2012, Accepted: 07-04-2012, Published Online: 28-07-2012
}

doi: $10.5455 /$ vetworld.2012.594-598

\begin{abstract}
Aim: A study was undertaken to assess the effect of shell color on the fertility and hatchability in three different breeds of chicken viz, Black Rock, Gramapriya and Vanaraja maintained at Government Poultry Farm, Durg (Chhattisgarh).

Materials and Methods: A total of 180 eggs from each breed (Black rock, Gramapriya and Vanaraja) were studied in each trial and total three trials were conducted. All the eggs were individually marked. Eggs were divided into Brown, Light Brown and Creamy White. Eggs were candled twice during incubation i.e. on $7^{\text {th }}$ and $18^{\text {th }}$ days. Fertility percent was calculated by number of fertile eggs divided by total numbers of eggs set for incubation multiplied by 100. Likewise hatchability was calculated on TES (total egg set basis) and FES (fertile egg set basis) by the formulae Data were analyzed by $\chi^{2}$-test

Results: The findings shown that the overall average for shell color among the three breeds, brown shell color (46.98\%) was found to be most frequent as compare to light brown $(43.02 \%)$ and creamy white (10.00\%) colors, respectively. The fertility percentage among three different classes of shell color of eggs irrespective of breeds or batches highest pooled mean was in brown shell color $(90.80 \%)$ followed by light brown $(85.22 \%)$ and creamy white $(83.33 \%)$. Whereas, on total egg set (TES) basis the hatchability percentage irrespective of breeds or hatches were 73.72 for brown, 67.00 for light brown and 52.47 for creamy white shell colored eggs, respectively and the pooled hatchability on fertile egg set (FES) basis, percentage followed same trend as in the case of hatchability on TES and brown shelled eggs group had higher hatchability rate with 81.19 percent followed by light brown $(78.62 \%)$ and creamy white $(62.96 \%)$, respectively.

Conclusion: It is concluded that dark colored eggs had higher fertility rate and also hatched at higher rate than did light colored eggs.

Key words: Black Rock, Fertility, Gramapriya, Hatchability, Shell color, Vanaraja.
\end{abstract}

To cite this article: Kumar A, Das K, Mukherjee K, Bharti A, Singh AK (2012) Frequency of different shell color and its effect on the fertility and hatchability in Black rock, Gramapriya and Vanraja breeds of chicken, Vet World, 5(10): 594-598, doi: 10.5455/vetworld.2012.594-598

\section{Introduction}

colored birds and brown shell colored eggs are preferred by the rural peoples, therefore so many improved varieties/breeds of chicken are introduced for backyard farming. Shell color is one of the important economic traits in poultry industries. Intensity of shell color varies within breed also as reported by [1]. Egg shell color has also been questioned in regards to its affects on hatchability by many workers. Workers like [2,3 and 4] observed that there were significant correlations between shell color and shell strength, thickness, and shell weight and due to this reason, thinner eggshells are associated with lowering in hatchability percentage, while thick- shelled eggs showed an increased hatchability as a result of greater fertility and lower intermediate and late embryonic mortalities. While workers [5]could not found distinct correlations between shell color and egg weight, albumen weight, yolk weight, haugh unit, yolk color of the Yangzhou chicken. In addition, they demonstrated that some egg quality traits such as shell strength, shell thickness, shell weight and shell ultrastructure could be assessed through the shell color. Limited studies are undertaken in our country in respect to fertility and hatchability of the improved varieties/breeds of chicken on the basis of shell color.

Thus, the present study was undertaken to observe the effect of shell color on the fertility and hatchability of Black Rock, Gramapriya and Vanaraja 
Frequency of different shell color and its effect on the fertility and hatchability in different breeds of chicken

Table-1. Frequency of different shell color groups in improved breeds of chicken.

\begin{tabular}{|c|c|c|c|c|}
\hline Breed & Set & Brown & Light B rown & Creamy White \\
\hline Gramapriya & $\begin{array}{l}\text { I } \\
\text { II } \\
\text { III } \\
\text { Pooled }\end{array}$ & $\begin{array}{l}107(59.44 \%) \\
94(52.22 \%) \\
106(58.89 \%) \\
307(56.85 \%)\end{array}$ & $\begin{array}{l}71(39.44 \%) \\
77(42.78 \%) \\
71(39.44 \%) \\
219(40.56 \%)\end{array}$ & $\begin{array}{l}2(1.11 \%) \\
9(5.00 \%) \\
3(1.67 \%) \\
14(2.59 \%)\end{array}$ \\
\hline Vanaraja & $\begin{array}{l}\text { I } \\
\text { II } \\
\text { III } \\
\text { Pooled } \\
\text { Overall }\end{array}$ & $\begin{array}{l}116(64.44 \%) \\
76(42.22 \%) \\
65(36.11 \%) \\
257(47.59 \%) \\
761(46.98 \%)\end{array}$ & $\begin{array}{l}54(30.00 \%) \\
76(42.22 \%) \\
96(53.33 \%) \\
226(41.85 \%) \\
697(43.02 \%)\end{array}$ & $\begin{array}{l}10(5.56 \%) \\
28(15.56 \%) \\
19(10.56 \%) \\
57(10.56 \%) \\
162(\mathbf{1 0 . 0 0 \% )}\end{array}$ \\
\hline
\end{tabular}

Values in the parenthesis are percentage (\%).

breeds of chicken.

\section{Materials and Methods}

Black Rock, Gramapriya and Vanaraja breeds of chicken were maintained in the Govt. Poultry Farm, Durg (Chhattisgarh) and of 28- 32 weeks of age. A total of 180 eggs from each breed were studied in each trial and total three trials were conducted. Duration between two trials was of one week (7 days). All the eggs were individually marked. Eggs were manually divided into three groups i.e. Brown, Light Brown and Creamy White. Then eggs were transferred to automated incubator for incubation. Eggs were candled twice during incubation i.e. on $7^{\text {th }}$ and $18^{\text {th }}$ days. Fertility percent was calculated by number of fertile eggs divided by total numbers of eggs set for incubation multiplied by 100 . Likewise hatchability was calculated on TES (total egg set basis) and FES (fertile egg set basis) by the formulae:

Hatchability \% (TES) = Number of egg hatched/ Total number of eggs set X 100

Hatchability \% (FES) = Number of egg hatched / Fertile eggs set X 100

Statistical Analysis: Data were analyzed by $\chi^{2}-$ test as suggested by authors [6] for test of independence.

\section{Results and Discussion}

While observing the overall average for shell color among the three breeds brown shell color $(46.98 \%)$ was found to be most frequent as compare to light brown (43.02\%) and creamy white (10.00\%) colors, respectively (Table-1). Gramapriya and Vanaraja breeds had same trend as overall pooled average with higher percentage of brown shell color followed by light brown and creamy white. However, in Black Rock, the light brown (46.67\%) was most frequent observed shell color. Gramapriya had highest frequency of brown shell color with 56.85 percent followed by Vanaraja with 47.59 percent and least percentage was observed in Black Rock (36.48\%). Least percentage was recorded for Gramapriya in light brown (40.56\%) and creamy white (only $2.59 \%$ ), whereas Black Rock was leading breed in these two groups with 46.67 and 16.85 percent, respectively and for Vanaraja frequency percentage was 41.85 and 10.56 percent, respectively. Parmar et al. [7] also observed that brown shell color were most frequent $(67.87 \%)$ in eggs of Kadaknath birds followed by light brown color (32.12\%). The shell color is mainly breed characteristic but it may be influenced by so many factors which may affect the frequency of different shell color of eggs. The most common factors are stress, age of the bird, chemotherapeutic agents and disease as reported by workers [8].

Results in Table-2, shows that there were highly significant $(\mathrm{P}<0.01)$ difference in fertility percentage among three different classes of shell color of eggs irrespective of breeds or batches. Highest pooled mean was in brown shell color $(90.80 \%)$ followed by light brown $(85.22 \%)$ and creamy white $(83.33 \%)$. However, no significant difference was found in Black Rock and Gramapriya breeds as well as in second batch among different shell color groups.

In present investigation brown shell colored eggs showed higher rate of fertility over light brown and creamy white shell colored eggs which was in accordance with workers [9], who also found differences in fertility rate in different shell colored eggs. Whereas, authors [10] did not found any 
Frequency of different shell color and its effect on the fertility and hatchability in different breeds of chicken

Table-2. Effect of shell color on the fertility and hatchability in improved breeds of fowl.

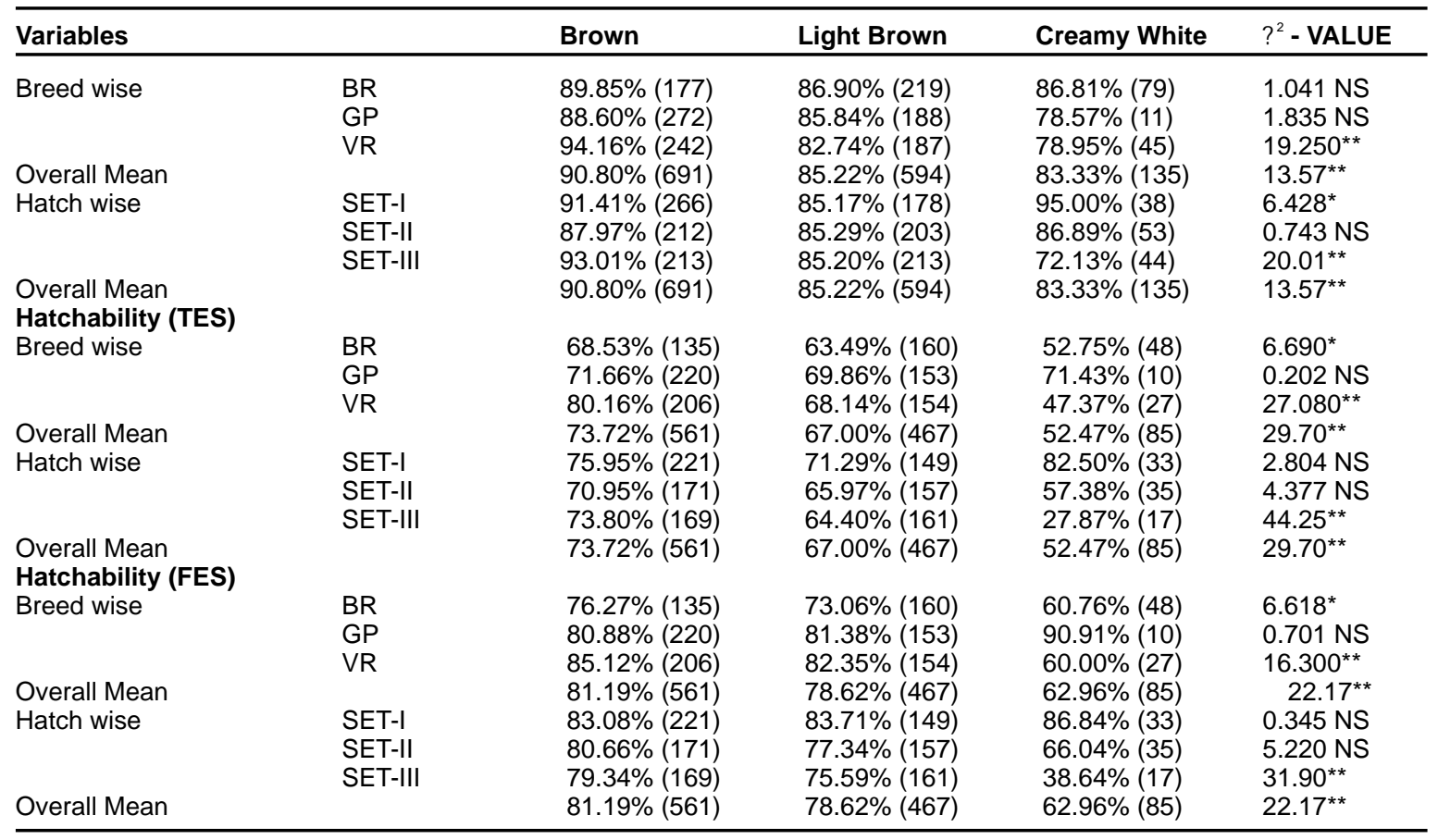

Values in the parenthesis are percentage (\%).

difference in fertility in different shell colored eggs. In the observation based on three shell color groups, the hatchability percentage on total egg set (TES) basis, irrespective of breeds or batches were 73.72 for brown, 67.00 for light brown and 52.47 for creamy white shell colored eggs, respectively (Table-2). The result revealed the influence of shell color on the hatchability of eggs (TES) which is in concur with earlier worker [11]. This difference of hatchability rate on the shell color of eggs was found highly significant $(\mathrm{P}<0.01)$, indicating the higher hatchability in brown shell colored eggs. However, no significant difference was observed among three different shell color groups of Gramapriya and hatches I and II. Most probable cause of lower hatchability in lighter color eggs might be due loss of higher moisture content and have less specific gravity, which result in low hatchability. Similar findings were observed by other worker [12], who reported lower hatchability percentage in white shelled eggs.

The data obtained for hatchability on fertile egg set (FES) on the basis of different shell color are presented in the Table-2. The pooled hatchability on FES percentage followed same trend as in the case of hatchability on TES and brown shelled eggs group had higher hatchability rate with 81.19 percent followed by light brown $(78.62 \%)$ and creamy white $(62.96 \%)$ respectively.

Results showed highly significant $(\mathrm{P}<0.01)$ difference among different shell color groups irrespective of breeds or hatches. However, $\chi^{2}-$ test could not reveal significant difference in the hatchability of three different shell color groups of Gramapriya and hatches I and II. The higher hatchability rate among brown shelled eggs was probably due to shell pigments which are deposited on shell just prior to the egg being laid and light egg color may be a sign of prematurely laid eggs caused by some type of environmental stress. Another reason might be due to the positive association of the density of pigment with hatchability, apart from thicker shell with more calcium and high specific gravity of brown shelled eggs. The results of present study also support the work of other workers [13-17] who also reported better hatchability rate in darker eggs.

\section{Conclusion}

The brown shelled eggs had higher hatchability rate on total eggs set and fertile eggs set basis. The results revealed highly significant $(\mathrm{P}<0.01)$ difference in three different classes of egg shell color. It is concluded that dark colored eggs had higher fertility rate and also hatched at higher rate than did light colored eggs. 

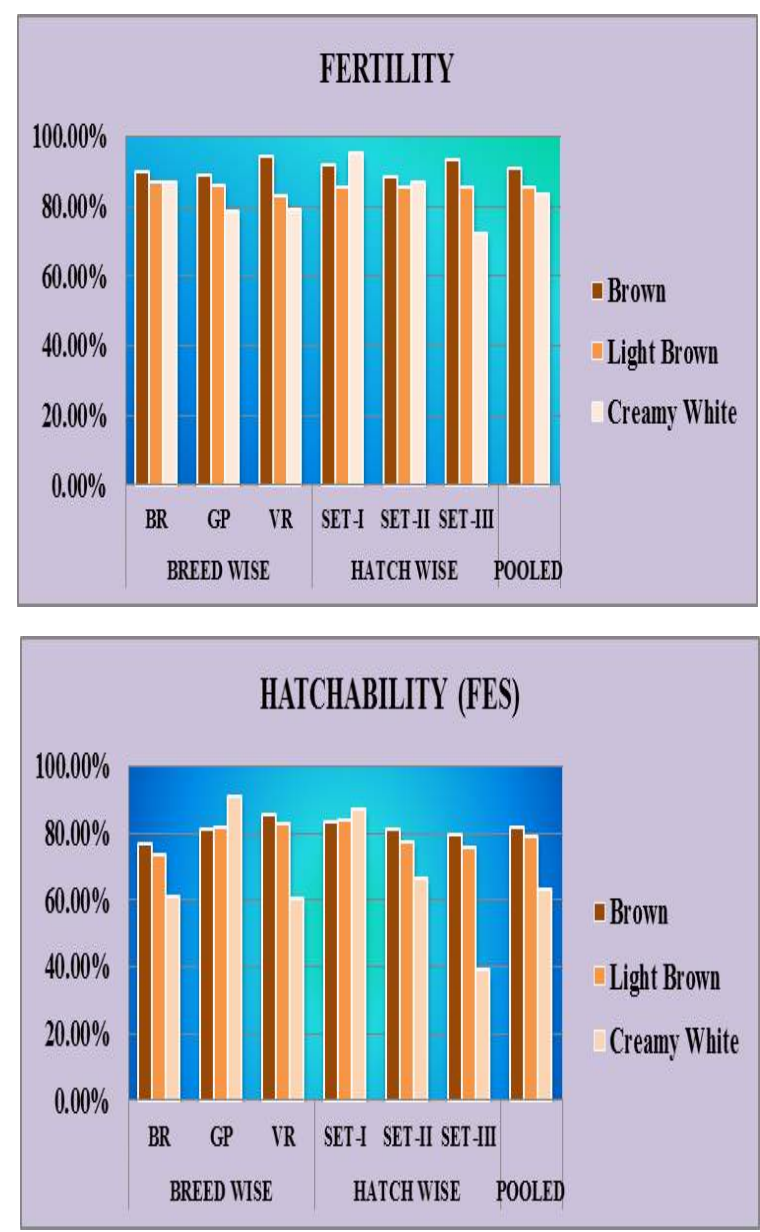

\section{Author's contribution}

Abhay Kumar, Keshab Das and Kishore Mukherjee participated in the preparation of experimental design and the facilities of the research. Abhay Kumar, Alok Bharti and Abhishek Kumar Singh analyzed the data, drafted and revised the manuscript. All the authors has read and approved the manuscript.

\section{Acknowledgements}

Authors are highly grateful to In-charge and other staff members of Government Poultry Farm, Durg (Chhattisgarh) for providing all necessary assistance and facilities during the research work in the Government Poultry Farm.

\section{References}

1. Krystianiak S., Kontecka H., Wę yk S., (2000). Pheasant's eggs quality depending on its eggshell color. In Polish, summary in English. Zeszyty Naukowe Przegladu Hodowlane go 49, 501.

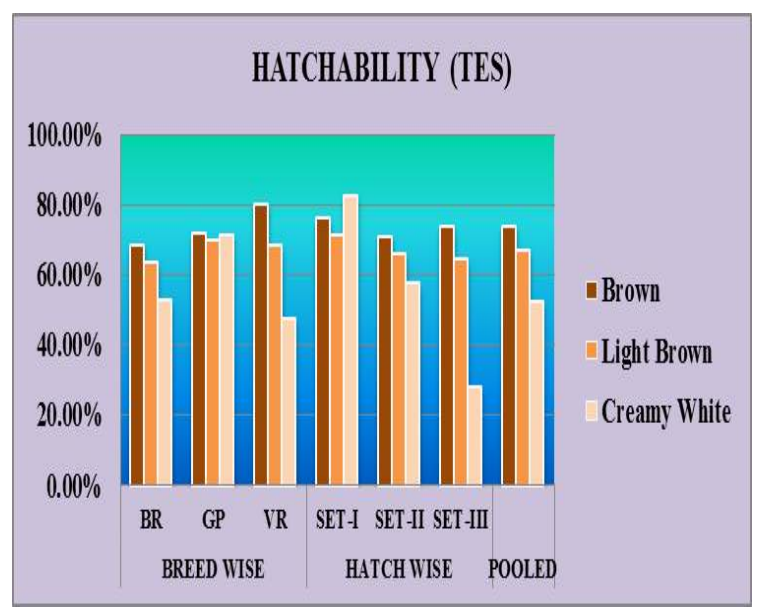

Effect of Shell color (Breed wise, Set wise and Overall) onthe Fertility and Hatchability on TES and FES.

2. McDaniel G.R., D. A. Roland and A. M. Coleman. (1979). The effect of eggshell quality on hatchability and embryonic mortality. Poultry Science 58 (1), 101 3

3. Bennett, C.D., (1992). The Influence of Shell Thickness on Hatchability in Commercial Broiler Breeder Flocks. J. Appl. Poult. Res., 1: 61-65.

4. Roque, L. and M. C. Soares. (1995). Effects of eggshell quality and broiler breeder age on hatchability. Poultry science 73(12):1838-45.

5. Yang, H. M., Z. Y. Wang and J. Lu. (2009). Study on the relationship between eggshell colors and egg quality as well as shell ultrastructure in Yangzhou chicken. African Journal of Biotechnology Vol. 8, pp. 2898-2902.

6. Snedecor, G.W. and Cochran, W.G. (1994). Statistical methods. $8^{\text {th }}$ edn. Oxford and IBH Publication, New Delhi.

7. Parmar, S.N.S., Thakur, M.S., Tomar, S.S. and Pillai, P.V.A. (2006). Evaluation of egg quality traits in indigenous Kadaknath breed of poultry. Department of Animal Breeding and Genetics, College of 
Veterinary Science and Animal Husbandry, JNKVV, Jabalpur (M. P.), India- 482001.

8. Chukwuka, O.K., Okoli, I.C., Okendo, N.J., Udedibie, A.B.I. and Ogbuewn, I.P. (2010). Egg quality defects in poultry management and food safety. Asian J. Agric. Res., 5: 1- 16.

9. Krystianiak, S., R. Kozuszek, H. Kontecka and S. Nowaczewski. (2005). Quality and ltrastructure of eggshell and hatchability of eggs in relation to eggshell color in pheasants. Animal Science Papers and Reports vol. 23, 5-14.

10. Hulet R. M., C. J. Flegal, G. H. Carpenter and L. R. Champion. (1985). Effect of eggshell color and thickness on hatchability in Chinese ring-necked pheasants. Poultry Science 64, 235-237.

11. Godfrey, G.F. (1947). The relationship of egg shell color to hatchability in some brown egg laying breeds. Poult. Sci., 26: 381-388.

12. Jull, M.A. (1952). Poultry Breeding. Third edition.
John Willey and Sons, New York.

13. North, M.O. (1972). Commercial Chicken Production Manual. The AVI Publ. Co. Inc., Westport.

14. Anonymous. (1993). Egg Production and Incubation. Fordingbridge: The Game Conservancy. 52-114.

15. Zgobica, A. and Wezyk, S. (1995). Relationship between external egg quality traits and hatchability of laying fowls. Zakad Hodowli Drobiu, Instytut Zootechniki, Balice k. Krakova, Poland. RocznikiNaukowe-Zootechniki. 22(1): 113-123.

16. Shafey, T.M., AL-Batshan, H.A., Ghannam, M.M and Al-Ayed, M.S. (2005). Effect of intensity of eggshell pigment and illuminated incubation on hatchability of brown eggs. Br. Poult. Sci. 46 (2): 190198.

17. Moyle, J., Yoho, D. and Bramwell, K. (2008). The effects of egg specific gravity and eggshell color on hatchability. University of Arkansas. In winter, 2009 issue of the Avian Advice. 